\title{
BMJ Open Cross-sectional comparative study of risky sexual behaviours among HIV- infected persons initiated and waiting to start antiretroviral therapy in rural Rakai, Uganda
}

\author{
Lydia Jacenta Nakiganda, ${ }^{1}$ Gertrude Nakigozi, ${ }^{2}$ Joseph Kagaayi, ${ }^{2}$ Fred Nalugoda, ${ }^{2}$ \\ David Serwadda, ${ }^{3}$ Nelson Sewankambo, ${ }^{4}$ Ronald Gray, ${ }^{5}$ Anthony Ndyanabo, ${ }^{2}$ \\ Richard Muwanika, ${ }^{2}$ Benedict Oppong Asamoah ${ }^{6}$
}

To cite: Nakiganda LJ, Nakigozi G, Kagaayi J, et al. Cross-sectional comparative study of risky sexual behaviours among HIV-infected persons initiated and waiting to start antiretroviral therapy in rural Rakai, Uganda. BMJ Open 2017;7:e016954. doi:10.1136/ bmjopen-2017-016954

- Prepublication history and additional material for this paper are available online. To view please visit the journal (http:// dx.doi.org/10.1136/bmjopen2017-016954).

Received 29 March 2017

Revised 25 July 2017

Accepted 3 August 2017

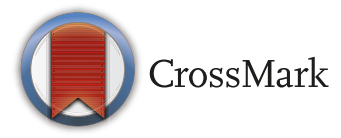

${ }^{1}$ International Master Programme in Public Health, Faculty of Medicine, Lund University, Malmö, Sweden

${ }^{2}$ Rakai Health Sciences Program, Kalisizo, Uganda

${ }^{3}$ Makerere University School of Public Health, Kampala, Uganda ${ }^{4}$ Makerere University College of Health Sciences, Kampala, Uganda

${ }^{5}$ School of Public Health, John Hopkins University, Maryland, USA

${ }^{6}$ Department of Clinical

Sciences, Division of Social Medicine and Global Health, Lund University, Malmö, Sweden

Correspondence to

Lydia Jacenta Nakiganda;

lydianakiganda85@gmail.com

\section{ABSTRACT}

Objectives To compare risky sexual behaviours between HIV-positive persons initiated on antiretroviral therapy (ART) (ART-experienced) and persons waiting to start on ART (ART-naive) and assess predictors of risky sexual behaviours among HIV-infected patients in rural Rakai district, Uganda.

Study design This is a cross-sectional study that used data from the Rakai Community Cohort Study (RCCS) database between 2013 and 2014. A structured questionnaire was used for data collection. We used stepwise logistic regression as an index to estimate the adjusted ORs for the association between risky sexual behaviours and ART treatment status.

Study setting This study was conducted in Rakai district, located in south-western Uganda. The data for this study were extracted from the RCCS. RCCS is an open prospective cohort of approximately 15000 consenting participants aged 15-49 years.

Participants HIV-positive participants aged 18-49 years who had sex at least once a month with any partner prior to the start of the study.

Main outcome measures Inconsistent/no condom use in the last 12 months, alcohol use at last sexual encounter, and two or more sexual partners.

Results ART-naive participants were more likely to report inconsistent condom use $(0 \mathrm{R}=1.74,95 \% \mathrm{Cl}$

1.11 to 2.73 ) and more likely to drink alcohol at last sexual encounter $(0 \mathrm{R}=1.65,95 \% \mathrm{Cl} 1.11$ to 2.46), compared with ART-experienced patients. ART treatment status $(p<0.001)$ was a significant predictor of risky sexual behaviours. Both marital status $(p=0.016)$ and occupation level $(p=0.009)$ were positively associated with inconsistent condom use, while sex $(p<0.001)$ correlated with alcohol use at last sexual encounter.

Conclusion ART-naive participants were more likely to exhibit risky sexual behaviours than the ARTexperienced participants. The intensity of risk reduction counselling should be increased for HIV-positive persons waiting to start ART but already in HIV care.
Strengths and limitations of this study

The study uses data from a prospective, populationbased study cohort, with a high participation rate of over $90 \%$, capturing a representative sample of the sexually active HIV-positive population in 54 surveyed communities. Findings are therefore generalisable and applicable to country-wide policies and interventions.

- Risky sexual behaviours estimates are based on self-reported measures, which are subject to social desirability and recall bias.

- Reporting condom use in the last 12 months may not always accurately characterise participants' overall condom use due to the long periods of measurement.

- This study did not consider the time element, CD4 cell count, calendar years or time on antiretroviral therapy, which may be factors that correlate with risky sexual behaviours.

- The period of observation was restricted to one survey round, which may not necessarily give accurate changes in exposure time measurements.

\section{INTRODUCTION}

Improved access to effective antiretroviral therapy (ART) has led to declines in morbidity and mortality rates among people living with HIV (PLHIV). ${ }^{2}$ ART is highly effective in reducing plasma levels of HIV RNA and reducing incidence of HIV-related opportunistic infections ${ }^{34}$; hence, people living with HIV and are on ART (ART-experienced) now live longer. ${ }^{56}$ Despite the beneficial effects of ART, risk of transmission is not completely eliminated, particularly for those who do not have complete viral suppression, or transmission from those where an undetectable viral load has been documented. ${ }^{78}$ 
Beneficial effects of ART include slower disease progression and reduced viral load, which have been met with optimism among HIV-positive people, as they no longer perceive HIV as a life-threatening ailment, ${ }^{9}{ }^{10}$ and many are aware that with treatment, HIV is a chronic manageable disease. ${ }^{11} 12$ This optimism has been associated with an increase in risky sexual behaviours. ${ }^{9} 1314$ In addition, the general physical health improvement and increased survival that follow ART may be accompanied by an increase in sexual desire and activity, ${ }^{15} 16$ which can lead to onward HIV transmission. There could also be an offset brought about by risky sexual behaviours. ${ }^{17}$ Cell-associated genital HIV shedding may occur in people with low HIV viral load, ${ }^{18} 19$ allowing for potential transmission of drug-resistant strains. ${ }^{20} \mathrm{HIV}$ transmission from people on ART will usually depend on the effectiveness of ART in reducing viral load and the efficiency of ART programme in reducing risky sexual behaviours.

Worldwide, risky sexual behaviours continue to be reported among PLHIV, ${ }^{21-24}$ increasing chances of transmission of drug-resistant strains from HIV-infected persons with incomplete viral suppression. ${ }^{20}$ It is estimated that about $7 \%-17 \%$ of newly infected persons in high-income countries ${ }^{25}$ and $4.8 \%-6.8 \%$ in low-income and middle-income countries ${ }^{26}$ carry at least one major drug resistance mutation. These resistant strains are not responsive to first-line ART therapy ${ }^{2027}$ and may require second-line ART regimens, which are prohibitively expensive in low-income countries. In addition, there is a risk of superinfection with drug-resistant strains that has been reported among PLHIV. ${ }^{28}$ Therefore, understanding risky sexual behaviours among HIV-positive persons is of great public health importance as it can provide useful insights in preventing further HIV transmission and enable PLHIV to lead healthy lives.

Early sexual debut, multiple sexual partnerships, limited and inconsistent condom use, sex under the influence of alcohol, childhood marriages and transactional cross-generational sex constitute the main risky behaviours currently driving the HIV epidemic in Uganda. ${ }^{30-32}$ In Uganda, ART is provided to all patients with a confirmed HIV diagnosis and CD4 count below 500 cells $/ \mathrm{mm}^{3}$, or at time of diagnosis among sex workers, fisherfolk, pregnant mothers, those infected with tuberculosis, children less than 15 years and serodiscordant couples, as per the Ugandan Ministry of Health guidelines. ${ }^{33}$ While in Kenya, ART treatment coverage is at $59 \%,{ }^{34}$ Uganda's ART treatment coverage is still suboptimal with only about 775212 patients out of $\sim 1.5$ million infected persons $(51 \%)$ on ART as of $2015 .{ }^{35}$ With improvements in access to ART and availability in Uganda, an increasing number of PLHIV are expected to live extended periods and healthier lives, so changes in their risky sexual behaviours could have an impact on HIV transmission.

However, the characteristics and behaviours of ART-naive persons (waiting to start ART) have received less attention maybe because they are not required to visit clinics more often for HIV care unlike the ART-experienced persons (those on ART). Most of the reviews done in Uganda have investigated risky sexual behaviours, with a focus on people already enrolled on ART, ${ }^{36-38}$ leaving out those not yet started on ART. The comparison between these two groups remains largely undocumented.

This study therefore compares risky sexual behaviours among ART-naïve and ART-experienced persons and explores the potential predictors of risky sexual behaviours among PLHIV attending an HIV treatment and care programme in rural Rakai.

\section{Conceptual framework}

In summary, the conceptual framework (see online supplementary figure 1) illustrates the possible factors for PLHIV to engage in risky sexual behaviours. In understanding these various factors influencing risky sexual behaviours, this model suggests two sets of characteristics: distal factors and proximate factors. The distal factors (age, educational level, occupation, socioeconomic status, gender, Antiretroviraltreatment status) and proximate factors (intensity of counselling, frequent health education, medical check-ups) are considered as independent factors affecting risky sexual behaviours, which are the dependent variables (outcomes). Intensity of counselling, frequent health education and continued medical check-ups could predict risky sexual behaviours. This has been seen in studies conducted in other low-income settings that predict intensity of behavioural change counselling and health education, ${ }^{39} 40$ medical check-ups and frequent hospital visits as factors in the reduction of risky sexual behaviours among PLHIV.

Using this conceptual framework, it is hypothesised that ART-experienced persons (those on ART) are more likely to drink alcohol on their last sexual encounter, have multiple sexual partners and use condoms inconsistently with any sexual partner. Thus it is predicted that proximate factors will moderate the differences in the risky sexual behaviours between ART-naïve and ART-experienced persons.

\section{METHODS}

This cross-sectional study was conducted among HIV-positive persons in Rakai, a rural district located in southwestern Uganda. Rakai district has a population of 518008 , with $80 \%$ of the population being agriculturalists. ${ }^{41}$ The data for this study was extracted from the Rakai Community Cohort Study (RCCS). RCCS is a prospective cohort, which has been described previously. ${ }^{43}$ It is an open, population-based cohort of approximately 15000 consenting participants aged $15-49$ years with an overall adult HIV prevalence of $13 \% .{ }^{44}$ Within this cohort, serosurveys have been conducted every 12-20 months since 1994. Structured interviews are administered by same-sex interviewers and participants provide blood samples for HIV serology and diagnosis of other sexually transmitted infections. Interviews establish information on sociodemographic characteristics, sexual behaviours, health and 
contextual characteristics. In this cross-sectional study, the data used was derived from round 15 (2013-2014).

\section{Eligibility criteria}

Participants were eligible to participate in the study if they had tested HIV-positive, were on ART or were ART-naive but in care, and had sex at least once a month with any partner (sexually active) prior to the start of the study. Only HIV seroconcordant persons were included in this study, irrespective of marital status.

\section{Variables}

The outcome variables in this study were risky sexual behaviours. Risky sexual behaviours in this study are described as any sexual behaviour that increases the likelihood of contracting Sexually Transmitted Infections or HIV. In this study, two or more sexual partners, alcohol use at last sexual encounter and inconsistent condom use (in the last 12 months) are all described as risky sexual behaviours. The independent variables included sociodemographics and ART treatment status.

\section{Dependent/outcome variables}

Inconsistent/no condom use was defined from a question about frequency of condom use in the last 12 months. The response alternatives were dichotomised as consistent condom use and inconsistent/no condom use for those who responded that they 'sometimes' or 'never' used condoms. Alcohol use at last sex was dichotomised as 'yes' or 'no'. Two or more sexual partners was defined as having either serial or concomitant partners within the past 12 months. Risky sex was described as those participants who either used condoms inconsistently, drank alcohol at last sex, or had two or more sexual partners in the last 12 months.

\section{Independent variables}

Previous studies ${ }^{45-47}$ identified several predictors associated with risky sexual behaviours among PLHIV. In this study, these variables were expected to correlate with risky behaviours among PLHIV: ART treatment status, which was recorded as ART-naive; people diagnosed as HIV-positive and referred for HIV care but are not yet started on antiretroviral treatment or ART-experienced status; people already enrolled on ART. Education level was classified as primary school level/did not attend school or secondary level or higher. Current marital status was categorised as currently married or unmarried. Age was grouped into three categories: 18-24, 25-34 and 35-50 years. Occupation was dichotomised into agriculture or any other occupation.

\section{Ethical consideration}

The Rakai Community Cohort Study was approved by the Research and Ethics Committee of the Uganda Virus Research Institute, the Uganda National Council of Science and Technology, and US-based Western Institutional Review Board. . Written informed consent was obtained from all research participants. For this study, no additional consent was needed as it is a secondary data analysis.

\section{Statistical methods}

IBM SPSS Statistics V.21 for Windows was used for statistical analysis. Contingency tables were used for bivariate analysis to examine associations between outcome variables (sexual behaviours) and covariates, and $\mathrm{X}^{2}$ tests were used for statistical inference. All covariates statistically significant in bivariate analyses were included in the multivariable analysis. Multivariable logistic regression was used to estimate adjusted ORs (adjOR) and 95\% CIs using stepwise selection, and statistical significance was based on a $p$ value less than 0.05 .

\section{RESULTS}

Table 1 describes the characteristics of the study participants stratified by ARV treatment status. This study had $341(66 \%)$ women and $176(34 \%)$ men. The majority of participants were married $(67.5 \%)$, agriculturalists $(55.7 \%)$, had primary or no education $(72.9 \%)$, and $55.7 \%$ were between $35-50$ years of age. The mean age of the respondents was 35.6 years $(\mathrm{SD}=6.67)$.

ART-naive participants reported a higher percentage of inconsistent or no condom use $(85.8 \%)$ compared with ART-experienced $(78.1 \%)$, and the difference was statistically significant $(\mathrm{p}=0.031)$. Alcohol use at last sex was reportedly lower in ART-experienced $(22.5 \%)$ compared to ART-naïve participants (32.5\%; $\mathrm{p}=0.012)$. Having two or more sexual partners was almost similar among ART-experienced (19.4\%) and ART-naïve persons $(18.3 \%) \quad(\mathrm{p}=0.756)$, while somewhat more ART-naïve participants did not use condoms at last sex compared with ART-experienced participants $(72.1 \%$ vs $64.7 \%$, respectively; $\mathrm{p}=0.081$ ).

For the bivariate analyses (table 2), inconsistent/no condom use was higher among the ART-naive compared with the ART-experienced participants $(\mathrm{OR}=1.69,95 \% \mathrm{CI}$ 1.04 to 2.73), and inconsistent/no condom use was more frequent among women compared with men $(65.9 \%$ vs $34.1 \% ; \mathrm{p}=0.932)$. Agriculturalists were more likely to report no/inconsistent condom use than any other occupations ( $\mathrm{OR}=1.80,95 \%$ CI 1.15 to 2.80$)$. Additionally, ART-naive participants had higher odds of drinking alcohol at last sexual encounter compared with ART-experienced participants $(\mathrm{OR}=1.65,95 \% \mathrm{CI} 1.11$ to 2.46$)$ (table 3). Men were more likely to drink alcohol at last sexual encounter compared with women $(\mathrm{OR}=3.40$, 95\% CI 2.26 to 5.12) (table 3).

Three predictor variables (table 2) were significantly associated with inconsistent condom use: ART treatment status $(\mathrm{p}=0.031)$, marital status $(\mathrm{p}=0.016)$ and occupation level $(\mathrm{p}=0.009)$. Table 3 shows both sex $(\mathrm{p}<0.001)$ and ART treatment status $(\mathrm{p}=0.013)$ as significant predictors in drinking alcohol at last sex.

In the final multivariate model (table 4), the association between inconsistent condom use and ART treatment 
Table 1 Baseline sociodemographic and sexual behaviour characteristics of 517 participants in a longitudinal cohort study of people living with HIV in a rural district, Rakai, Uganda

\begin{tabular}{|c|c|c|c|c|}
\hline Characteristics & Overall (\%) & ART-naive (\%) & $\begin{array}{l}\text { ART-experienced } \\
(\%)\end{array}$ & p Value* \\
\hline Overall & & $197(38.1)$ & $320(61.9)$ & \\
\hline \multicolumn{5}{|l|}{ Sex } \\
\hline Female & $341(66.0)$ & $130(66.0)$ & $211(65.9)$ & 0.990 \\
\hline Male & $176(34.0)$ & 67 (34.0) & $109(34.1)$ & \\
\hline \multicolumn{5}{|l|}{ Age (years) } \\
\hline Mean (SD) & $35.55(6.48)$ & $36.34(6.25)$ & $34.27(6.60)$ & $<0.001$ \\
\hline Median (IQR) & $35.0(31-40)$ & $37(30-41)$ & 34 (30-39) & \\
\hline \multicolumn{5}{|l|}{ Age group (years) } \\
\hline $18-24$ & $23(4.4)$ & $13(6.6)$ & 10) (3.1) & 0.004 \\
\hline $25-34$ & $206(39.8)$ & $91(46.2)$ & $115(35.9)$ & \\
\hline $35-50$ & $288(55.7)$ & $93(47.2)$ & $195(60.9)$ & \\
\hline \multicolumn{5}{|l|}{ Marital status } \\
\hline Married & $349(67.5)$ & $137(69.5)$ & $212(66.3)$ & 0.438 \\
\hline Not married & $168(32.5)$ & $60(30.5)$ & 108 (33.8) & \\
\hline \multicolumn{5}{|l|}{ Main occupation } \\
\hline Agriculture/housework & $288(55.7)$ & $113(57.4)$ & $175(54.7)$ & 0.552 \\
\hline Other occupation & $229(44.3)$ & $84(42.6)$ & $145(45.3)$ & \\
\hline \multicolumn{5}{|l|}{ Education level } \\
\hline Primary or lower & 377 (72.9) & $137(69.5)$ & $240(75.0)$ & 0.175 \\
\hline Secondary or higher & $140(27.1)$ & $60(30.5)$ & 80 (25.0) & \\
\hline \multicolumn{5}{|c|}{ Alcohol use at last sexual encounter } \\
\hline Yes & $136(26.3)$ & $64(32.5)$ & $72(22.5)$ & 0.012 \\
\hline No & $381(73.7)$ & $133(67.5)$ & $248(77.5)$ & \\
\hline \multicolumn{5}{|c|}{ Condom use in the last 12 months } \\
\hline Consistent & 98 (19.0) & $28(14.2)$ & 70 (21.9) & 0.031 \\
\hline Inconsistent & $419(81.0)$ & $169(85.8)$ & $250(78.1)$ & \\
\hline \multicolumn{5}{|l|}{ Number of sexual partners } \\
\hline 1 partner & $419(81.0)$ & $161(81.7)$ & $258(80.6)$ & 0.756 \\
\hline 2 or more partners & $98(19.0)$ & $36(18.3)$ & $62(19.4)$ & \\
\hline \multicolumn{5}{|c|}{ Condom use at last sexual encounter } \\
\hline Yes & $168(32.5)$ & $55(27.9)$ & $113(35.3)$ & 0.081 \\
\hline No & 349 (67.5) & $142(72.1)$ & 207 (64.7) & \\
\hline
\end{tabular}

*p Value from $\chi^{2}$ test.

ART, antiretroviral therapy.

status remained statistically significant after adjusting for age, occupation and marital status (adjOR=1.47 95\% CI 0.90 to 2.41 , model 4 ). Age and sex were significantly associated with alcohol consumption: adjOR $=3.47,95 \%$ CI 2.30 to 5.23 for sex, and OR=3.34, 95\% CI 0.74 to 15.03 for age (table 5).

\section{DISCUSSION}

Findings from this study reveal ART-naive participants having slightly increasing odds of practising risky sexual behaviours compared with participants on ART. This is similar to other studies done that showed ART-naive

patients were more likely to practise risky sexual behaviours than the ART-experienced patients. ${ }^{154}$ These differences could be attributed to the variability in counselling intensity, health education and follow-ups given to patients on ART, compared with ART-naive patients (patients on ART are required to visit the clinic more frequently than those on ART).

Sex and age are significant predictors of risk sexual behaviours among HIV-positive patients in this study. This is related to studies done before that have either identified sex or age as significant predictors of risky sexual behaviours. ${ }^{45} 4849$ 
Table 2 Association (crude ORs, 95\% Cls) between sociodemographic factors, ART treatment status and inconsistent condom use in a sample of 517 HIV-positive patients in Rakai: results of logistic regression

\begin{tabular}{|c|c|c|c|c|}
\hline & Consistent, n (\%) & $\begin{array}{l}\text { Inconsistent/no } \\
\text { condom use, n (\%) }\end{array}$ & Crude ORs $(95 \% \mathrm{Cl})$ & p Value* \\
\hline \multicolumn{5}{|l|}{ ART treatment status } \\
\hline ART-naïve & $28(28.6)$ & $169(40.3)$ & 1.69 (1.04 to 2.73$)$ & 0.031 \\
\hline ART-experienced & 70 (71.4) & $250(59.7)$ & 1 (ref group) & \\
\hline \multicolumn{5}{|l|}{ Sex } \\
\hline Male & $33(33.7)$ & $143(34.1)$ & 1.02 (0.64 to 1.62$)$ & 0.932 \\
\hline Female & 65 (66.3) & 276 (65.9) & 1 (ref group) & \\
\hline \multicolumn{5}{|l|}{ Age } \\
\hline $25-34$ & $26(26.5)$ & $180(43.0)$ & 0.32 (0.041 to 2.43$)$ & 0.268 \\
\hline $35-50$ & $71(72.4)$ & 217 (51.8) & $0.13(0.02$ to 1.04$)$ & 0.056 \\
\hline $18-24$ & $1(4.3)$ & $22(5.3)$ & 1 (ref group) & \\
\hline \multicolumn{5}{|l|}{ Marital status } \\
\hline Married & $56(57.1)$ & $293(69.9)$ & 1.74 (1.11 to 2.73$)$ & 0.016 \\
\hline Not married & $42(42.9)$ & $126(30.1)$ & 1 (ref group) & \\
\hline \multicolumn{5}{|l|}{ Education level } \\
\hline Primary level & $68(69.4)$ & $309(73.7)$ & $1.23(0.76$ to 2.00$)$ & 0.383 \\
\hline Secondary level & $30(30.6)$ & $110(26.3)$ & 1 (ref group) & \\
\hline \multicolumn{5}{|l|}{ Occupation level } \\
\hline Agriculture/housework & $43(43.9)$ & $245(58.5)$ & 1.80 (1.15 to 2.80$)$ & 0.009 \\
\hline Other occupation & $55(56.1)$ & $174(41.5)$ & 1 (ref group) & \\
\hline
\end{tabular}

${ }^{*} \mathrm{p}$ Value from $\chi^{2}$ test.

ART, antiretroviral therapy.

Almost $81 \%$ of participants within the study reported inconsistent condom use, which indicates high prevalence of unsafe sex among HIV-positive people. This highlights the dangers of continued HIV transmission despite the increasing ART roll-out. Therefore, these findings call for increasing awareness and motivation for condom use among HIV-positive patients. Additionally, inconsistent condom use was more likely among ART-naïve patients, a finding similar to earlier studies in Uganda,${ }^{15}$ Kenya $^{50}$ and South Africa. ${ }^{48}$ These findings could be due to more secondary HIV prevention programmes given to ART-experienced patients as they visit ART clinics often for refills and medical check-ups.

Inconsistent condom use was higher among women than in men (65.9\% vs $34.1 \%$ ) in this study. This is similar to studies done in Italy that showed almost $44.3 \%$ of HIV-positive women were inconsistent condom users. ${ }^{51}$ This could reflect the limitations of female bargaining power within sexual relationships. A central feature of Ugandan society is gender inequality, with women occupying subordinate roles both in economic activities and in decision-making. Women are not culturally empowered to negotiate sexually related issues, and this pattern of male control of sexual decision-making was also noted in Uganda and Rwanda ${ }^{52}{ }^{53}$ However, inconsistent condom use in this group could also be attributed to the desire to have children. Studies ${ }^{54} 55$ have shown reproductive desires play a significant role in the lives of HIV-positive women. Therefore, these gender differences highlight a need of incorporating gender dynamics in secondary prevention strategies in order to meet the specific needs of both women and men.

We observed almost $26 \%$ of HIV-positive patients consumed alcohol before sex. This is a health concern because alcohol consumption among HIV-positive persons has been associated with decreased adherence to $A R V,{ }^{567}$ reducing the patient's ability to practise safer sex. ${ }^{58}$ Additionally, ART-naive participants were more likely to consume alcohol at their last sexual encounter compared with ART-experienced participants. This could be explained by the fact that once people are started on ART, they are advised not to drink or certainly take limited amounts of alcohol in order to preserve the integrity of their liver, ${ }^{596}$ so that the ARVs are well processed in the body. Another reason could be the guidelines and adherence support counselling given by health workers when on ART. These findings are aligned with a study that reported decreased alcohol consumption after ART initiation $^{61}$ and higher odds of alcohol consumption during the pre-ART period. ${ }^{21}$

In this study, men were three times more likely to drink alcohol at their last sexual encounter. This could be attributed to the common social values and the acceptance of male drinking in society. A Ugandan study 
Table 3 Association (crude ORs, 95\% Cl) between sociodemographic factors, ART treatment status and alcohol use at last sexual encounter in a sample of 517 HIV-positive patients in Rakai: results of logistic regression

\begin{tabular}{|c|c|c|c|c|}
\hline & Alcohol use Yes, n (\%) & Alcohol use No, n (\%) & Crude ORs $(95 \% \mathrm{Cl})$ & p Value* \\
\hline \multicolumn{5}{|l|}{ ART treatment status } \\
\hline ART-naive & $64(47.1)$ & $133(34.9)$ & 1.65 (1.11 to 2.46$)$ & 0.013 \\
\hline ART-experienced & $72(52.9)$ & $248(65.1)$ & Ref & \\
\hline \multicolumn{5}{|l|}{ Sex } \\
\hline Male & $75(55.1)$ & $101(26.5)$ & 3.40 (2.26 to 5.12$)$ & $<0.001$ \\
\hline Female & $61(44.9)$ & $280(73.5)$ & Ref & \\
\hline \multicolumn{5}{|l|}{ Age } \\
\hline $35-50$ & $82(60.3)$ & $206(54.1)$ & 4.18 (0.95 to 18.22$)$ & 0.057 \\
\hline $25-34$ & $52(38.2)$ & $154(40.4)$ & 3.54 (0.80 to 15.63$)$ & 0.095 \\
\hline $18-24$ & $2(1.5)$ & $21(5.5)$ & Ref & \\
\hline \multicolumn{5}{|l|}{ Marital status } \\
\hline Married & $92(67.6)$ & $257(67.5)$ & $1.0(0.66$ to 1.53$)$ & 0.967 \\
\hline Not married & $44(32.4)$ & $124(32.4)$ & Ref & \\
\hline \multicolumn{5}{|l|}{ Education level } \\
\hline Primary level & 106 (77.9) & $271(71.1)$ & 1.43 (0.90 to 2.27$)$ & 0.126 \\
\hline Secondary level & $30(22.1)$ & $110(28.9)$ & Ref & \\
\hline \multicolumn{5}{|l|}{ Occupation level } \\
\hline Agriculture/housework & $70(51.5)$ & $218(57.2)$ & $0.79(0.53$ to 1.17$)$ & 0.247 \\
\hline Other occupation & $66(48.5)$ & $163(42.8)$ & Ref & \\
\hline
\end{tabular}

${ }^{*} p$ value from $\chi^{2}$ test.ART, antiretroviral therapy.

reported $41 \%$ of men consume alcohol before sex. ${ }^{62}$ It is recommended that addressing alcohol abuse should be a key focus in secondary prevention interventions. Healthcare providers should screen their patients with HIV for alcohol use problems and initiate interventions that can reduce alcohol-related problems among PLHIV. More research is needed to find and test different behavioural, social and biomedical interventions for alcohol-related problems among PLHIV.

Table 4 Association (adjusted OR, 95\% Cl) between inconsistent/no condom use and ART treatment status among 517 HIVpositive patients in Rakai: results of multivariate logistic regressions

\begin{tabular}{|c|c|c|c|c|}
\hline & Model 1 OR $(95 \% \mathrm{Cl})$ & Model 2 OR $(95 \% \mathrm{Cl})$ & Model 3 OR $(95 \% \mathrm{Cl})$ & Model 4 OR $(95 \% \mathrm{Cl})$ \\
\hline \multicolumn{5}{|l|}{ ART treatment status } \\
\hline ART-naive & 1.69 (1.04 to 2.73$)$ & 1.51 (0.92 to 2.46$)$ & 1.48 (0.90 to 2.42$)$ & 1.47 (0.90 to 2.41$)$ \\
\hline ART-experienced & Ref & Ref & Ref & Ref \\
\hline \multicolumn{5}{|l|}{ Age } \\
\hline $35-50$ & & 0.15 (0.02 to 1.15$)$ & $0.15(0.02$ to 1.21$)$ & $0.16(0.02$ to 1.23$)$ \\
\hline $25-34$ & & 0.33 (0.43 to 2.55$)$ & 0.34 (0.04 to 2.72 ) & 0.35 (0.04 to 2.77 ) \\
\hline $18-24$ & & Ref & Ref & Ref \\
\hline \multicolumn{5}{|l|}{ Occupation level } \\
\hline Agriculture/housework & & & 1.79 (1.14 to 2.81$)$ & 1.71 (1.00 to 2.53 ) \\
\hline Other occupation & Ref & Ref & Ref & Ref \\
\hline \multicolumn{5}{|l|}{ Marital status } \\
\hline Married & & & & 1.59 (1.00 to 2.53$)$ \\
\hline Not married & & & & Ref \\
\hline
\end{tabular}

Model 1: unadjusted model.

Model 2: adjusted for age.

Model 3: adjusted for age and occupation.

Model 4: adjusted for age, occupation and marital status.

ART, antiretroviral therapy. 
Compared with other studies in sub-Saharan Africa, ${ }^{63-65}$ this study found that participants with primary or lower level education were more likely to use condoms inconsistently. This could be explained by the fact that participants with higher education are more likely to have higher knowledge of HIV and are more informed.

\section{Methodological considerations}

The use of data from a population-based prospective cohort study with a high participation rate of over $90 \%$ that captured a representative sample of the sexually active HIV-positive population in 54 surveyed communities in rural Rakai communities makes the findings generalisable and applicable to country-wide policies and interventions. However this study had limitations. First, this was a cross-sectional study and could not derive causal inferences. Second, risky sexual behaviour estimates are based on self-reported measures, which are subject to social desirability and recall bias. However, a study done in Uganda showed large cohort studies have correlations between behavioural self-reported measures and HIV infection, thus suggesting that recall bias does not necessarily conceal key associations. ${ }^{66}$ It is therefore less likely that these potential biases would impact differences between the two groups. Third, reporting condom use in the last 12 months may not always accurately characterise patients' overall condom use due to the long periods of measurement. The frequency of condom use as well as recalling sexual encounters in the last 12-18 months since the last survey done might affect people's ability to accurately answer and remember details of sexual encounters. However, findings from other shorter time periods do not necessarily differ from the findings of this study, which may be a minor factor. ${ }^{67}$ Fourth, this study did not consider the time element; CD4 cell count and calendar years as well as time on ART may be factors that correlated with risky sexual behaviour. In addition, the period of observation was restricted to one survey round, which may not necessarily give accurate changes in exposure time measurements.

\section{CONCLUSION}

This study indicates that ART-naive participants have slightly increased odds of risky sexual behaviours compared with participants on ART. These differences may be attributed to the variability in counselling intensity, health education and follow-ups offered to patients on ART. Although findings reveal higher odds of risky sexual behaviours among ART-naive persons, rates of risky behaviour are high for both groups, and positive prevention programmes should be able to target both groups.

Focused interventions such as risk reduction counselling and education programmes are required to be incorporated in HIV care and treatment programmes, and emphasis should be laid on counselling to avoid reinfections and alcohol abuse. The roll-out of ART should not be considered as a single preventive intervention, but should be facilitated with other elements such as psychosocial support, gender dynamics, mental health services, nutrition and family planning to ensure a successful HIV fight. Better understanding of the underlying mechanisms and correlations of such high-risk sexual behaviour among persons living with HIV remains a priority for researchers and public health professionals alike.

Contributors LJN conceptualised the study, designed, analysed and drafted the first version of the manuscript. BOA and GN were involved in the analysis, interpretation and critical review of the manuscript. JK, FN, DS and NS were involved in revising the article critically for important intellectual content. RM edited and approved the final version to be published. AN was involved in the acquisition of data, data analysis and interpretation of the data.

Funding This research received no specific grant from any funding agency in the public, commercial or not-for-profit sector.

Competing interests None declared.

Table 5 Association (adjusted OR, 95\% Cl) between alcohol use at last sexual encounter and ART treatment status among 517 HIV-positive patients in Rakai: results of multivariate logistic regression

\begin{tabular}{|c|c|c|c|}
\hline & Model 1 OR $(95 \% \mathrm{Cl})$ & Model 2 OR $(95 \% \mathrm{Cl})$ & Model 3 OR $(95 \% \mathrm{Cl})$ \\
\hline \multicolumn{4}{|l|}{ ART treatment status } \\
\hline ART-naive & 1.65 (1.11 to 2.46$)$ & 1.72 (1.14 to 2.61$)$ & 1.80 (1.18 to 2.74$)$ \\
\hline \multicolumn{4}{|l|}{ Sex } \\
\hline Male & & 3.47 (2.30 to 5.23$)$ & 3.29 (2.17 to 4.99$)$ \\
\hline \multicolumn{4}{|l|}{ Age } \\
\hline $35-50$ & & & $3.34(0.74$ to 15.03$)$ \\
\hline $25-34$ & & & $2.95(0.65$ to 13.35$)$ \\
\hline $18-24$ & & & Ref \\
\hline
\end{tabular}

Model 1: unadjusted model.

Model 2: adjusted for sex.

Model 3: adjusted for age and sex.

ART, antiretroviral therapy. 
Ethics approval Research and Ethics Committee of the Uganda Virus Research Institute, the Uganda National Council of Science and Technology, and US-based Western IRB.

\section{Provenance and peer review Not commissioned; externally peer reviewed.}

Data sharing statement The data sets used for this study are available on request from the Rakai Community Cohort Study database at Rakai Health Sciences Program (www.rhsp.org).

Open Access This is an Open Access article distributed in accordance with the Creative Commons Attribution Non Commercial (CC BY-NC 4.0) license, which permits others to distribute, remix, adapt, build upon this work non-commercially, and license their derivative works on different terms, provided the original work is properly cited and the use is non-commercial. See: http://creativecommons.org/ licenses/by-nc/4.0/

(c) Article author(s) (or their employer(s) unless otherwise stated in the text of the article) 2017. All rights reserved. No commercial use is permitted unless otherwise expressly granted.

\section{REFERENCES}

1. Walker AS, Ford D, Gilks CF, et al. Daily co-trimoxazole prophylaxis in severely immunosuppressed HIV-infected adults in Africa started on combination antiretroviral therapy: an observational analysis of the DART cohort. Lancet 2010;375:1278-86.

2. Mermin J, Lule J, Ekwaru JP, et al. Effect of co-trimoxazole prophylaxis on morbidity, mortality, CD4-cell count, and viral load in HIV infection in rural Uganda. Lancet 2004;364:1428-34.

3. Castilla J, Del Romero J, Hernando V, et al. Effectiveness of highly active antiretroviral therapy in reducing heterosexual transmission of HIV. J Acquir Immune Defic Syndr 2005;40:96-101.

4. Porco TC, Martin JN, Page-Shafer KA, et al. Decline in HIV infectivity following the introduction of highly active antiretroviral therapy. AIDS 2004;18:81-8.

5. Nakagawa F, May M, Phillips A. Life expectancy living with HIV: recent estimates and future implications. Curr Opin Infect Dis 2013;26:17-25.

6. Nakagawa F, Lodwick RK, Smith CJ, et al. Projected life expectancy of people with HIV according to timing of diagnosis. AIDS 2012;26:335-43.

7. Attia S, Egger M, Müller M, et al. Sexual transmission of HIV according to viral load and antiretroviral therapy: systematic review and meta-analysis. AIDS 2009;23:1397-404.

8. Stürmer M, Doerr HW, Berger A, et al. Is transmission of HIV-1 in non-viraemic serodiscordant couples possible? Antivir Ther 2008;13:729-32.

9. Van de Ven P, Prestage G, Crawford J, et al. Sexual risk behaviour increases and is associted with HIV optimism among HIV-negative and HIV-positive gay men in Sydney over the 4 year period to February 2000. AIDS 2000;14:2951-3.

10. Remien RH, Wagner G, Carballo-Diéguez A, et al. Who may be engaging in high-risk sex due to medical treatment advances? AIDS 1998;12:1560-1.

11. Gray RH, Li X, Wawer MJ, et al. Stochastic simulation of the impact of antiretroviral therapy and HIV vaccines on HIV transmission; Rakai, Uganda. AIDS 2003;17:1941-51.

12. Salomon JA, Murray CJ. Modelling HIV/AIDS epidemics in subSaharan Africa using seroprevalence data from antenatal clinics. Bull World Health Organ 2001;79:596-607.

13. Luchters S, Sarna A, Geibel S, et al. Safer sexual behaviors after 12 months of antiretroviral treatment in Mombasa, Kenya: a prospective cohort. AIDS Patient Care STDS 2008;22:587-94.

14. Crepaz N, Lyles CM, Wolitski RJ, et al. Do prevention interventions reduce HIV risk behaviours among people living with HIV? A metaanalytic review of controlled trials. AIDS 2006;20:143-57.

15. Bateganya M, Colfax G, Shafer LA, et al. Antiretroviral therapy and sexual behavior: a comparative study between antiretroviral- naive and -experienced patients at an urban HIV/AIDS care and research center in Kampala, Uganda. AIDS Patient Care STDS 2005;19:760-8.

16. Newell ML. Vertical transmission of HIV-1 infection. Trans $R$ Soc Trop Med Hyg 2000;94:1-2.

17. Katz MH, Schwarcz SK, Kellogg TA, et al. Impact of highly active antiretroviral treatment on HIV seroincidence among men who have sex with men: San Francisco. Am J Public Health 2002;92:388-94.

18. Fiore JR, Suligoi B, Saracino A, et al. Correlates of HIV-1 shedding in cervicovaginal secretions and effects of antiretroviral therapies. AIDS 2003;17:2169-76.
19. Kovacs A, Wasserman SS, Burns D, et al. Determinants of HIV-1 shedding in the genital tract of women. The Lancet 2001;358:1593-601.

20. Little SJ, Holte S, Routy JP, et al. Antiretroviral-drug resistance among patients recently infected with HIV. N Engl J Med 2002;347:385-94.

21. Eisele TP, Mathews $C$, Chopra M, et al. High levels of risk behavior among people living with HIV Initiating and waiting to start antiretroviral therapy in Cape Town South Africa. AIDS Behav 2008;12:570-7.

22. Stolte IG, Dukers NH, Geskus RB, et al. Homosexual men change to risky sex when perceiving less threat of HIV/AIDS since availability of highly active antiretroviral therapy: a longitudinal study. AIDS 2004;18:303-9.

23. Ostrow DE, Fox KJ, Chmiel JS, et al. Attitudes towards highly active antiretroviral therapy are associated with sexual risk taking among HIV-infected and uninfected homosexual men. AIDS 2002;16:775-80.

24. Dukers NH, Goudsmit J, de Wit JB, et al. Sexual risk behaviour relates to the virological and immunological improvements during highly active antiretroviral therapy in HIV-1 infection. AIDS 2001;15:369-78.

25. Frentz D, Boucher CA, van de Vijver DA. Temporal changes in the epidemiology of transmission of drug-resistant HIV-1 across the world. AIDS Rev 2012;14:17-27.

26. World Health Organization. The HIV drug resistance report-2012.

27. Grant RM, Hecht FM, Warmerdam M, et al. Time trends in primary HIV-1 drug resistance among recently infected persons. JAMA 2002;288:181-8.

28. Jost S, Bernard MC, Kaiser L, et al. A patient with HIV-1 superinfection. N Engl J Med 2002;347:731-6.

29. Altfeld M, Allen TM, Yu XG, et al. HIV-1 superinfection despite broad $\mathrm{CD} 8+\mathrm{T}$-cell responses containing replication of the primary virus. Nature 2002;420:434-9.

30. Uganda AIDS Commission. National HIV and AIDS Strategic Plan 2015/2016 - 2019/2020.

31. Ministry of Health. Uganda HIVIAIDS country progress report http:// www.unaids.org/sites/default/files/country/documents/UGA narrative_report_2015.

32. UAC. National HIV prevention strategy 2011-15 for uganda. 2010.

33. Uganda Ministry of Health. National antiretroviral treatment guidelines. Updated $2013 \mathrm{http}: / /$ www.kisiizihospital.org.ug/ wp-content/uploadedfiles/2013/10/Addednum-National-ART-RxGuidelines-Dec-20

34. World Bank. Antiretorviral therapy coverage.. http://data.worldbank. org/indicator/SH.HIV.ARTC.ZS?locations. Updated 2016

35. Ministry of Health DHIS. Uganda's electronic health information system http://hmis2.health.go.ug/hmis2/dhis-web-commons/secur ity/login.action;jsessionid=90EEDE4E25C3E574DA736EE75491034E

36. Kembabazi A, Bajunirwe F, Hunt PW, et al. Disinhibition in risky sexual behavior in men, but not women, during four years of antiretroviral therapy in rural, southwestern Uganda. PLOS One 2013;8:e69634.

37. Wandera B, Kamya MR, Castelnuovo B, et al. Sexual behaviors over a 3-year period among individuals with advanced HIV/AIDS receiving antiretroviral therapy in an urban HIV clinic in Kampala, Uganda. $J$ Acquir Immune Defic Syndr 2011;57:62-8.

38. Bunnell R, Ekwaru JP, Solberg P, et al. Changes in sexual behavior and risk of HIV transmission after antiretroviral therapy and prevention interventions in rural Uganda. AIDS 2006;20:85-92.

39. Zajac K, Kennedy CE, Fonner VA, et al. A Systematic Review of the Effects of Behavioral Counseling on Sexual Risk Behaviors and HIV/ STI Prevalence in Low- and Middle-Income Countries. AIDS Behav 2015;19:1178-202.

40. Peltzer K, Tabane C, Matseke G, et al. Lay counsellor-based risk reduction intervention with HIV positive diagnosed patients at public HIV counselling and testing sites in Mpumalanga, South Africa. Eval Program Plann 2010;33:379-85.

41. Uganda Bureau of Statistics. Uganda statistical abstract. 2014.

42. Wawer MJ, Sewankambo NK, Serwadda D, et al. Control of sexually transmitted diseases for AIDS prevention in Uganda: a randomised community trial. Rakai Project Study Group. Lancet 1999;353:525-35.

43. Wawer MJ, Gray RH, Sewankambo NK, et al. A randomized, community trial of intensive sexually transmitted disease control for AIDS prevention, Rakai, Uganda. AIDS 1998;12:1211-25.

44. UAIS. Uganda AIDS indicator survey, 2011. Updated 2011. http:// health.go.ug/docs/UAIS_2011_REPORT.pdf.

45. Angdembe MR, Lohani SP, Karki DK, et al. Sexual behaviour of people living with HIV attending a tertiary care government hospital in Kathmandu, Nepal: a cross sectional study. BMC Res Notes 2015;8:1. 
46. Reilly T, Woo G. Predictors of high-risk sexual behavior among people living with HIV/AIDS. AIDS Behav 2001;5:205-17.

47. Heckman TG, Kelly JA, Somlai AM. Predictors of continued high-risk sexual behavior in a community sample of persons living with HIV/ AIDS. AIDS Behav 1998;2:127-35.

48. McGrath N, Richter L, Newell ML. Sexual risk after HIV diagnosis: a comparison of pre-ART individuals with CD4>500 cells $/ \mu$ and ARTeligible individuals in a HIV treatment and care programme in rural KwaZulu-Natal, South Africa. J Int AIDS Soc 2013;16:18048.

49. Musinguzi G, Bwayo D, Kiwanuka N, et al. Sexual behavior among persons living with HIV in Uganda: implications for policy and practice. PLoS One 2014;9:e85646.

50. Sarna A, Luchters SM, Geibel S, et al. Sexual risk behaviour and HAART: a comparative study of HIV-infected persons on HAART and on preventive therapy in Kenya. Int J STD AIDS 2008:19:85-9.

51. Cicconi P, Monforte A, Castagna A, et al. Inconsistent condom use among HIV-positive women in the "Treatment as Prevention Era": data from the Italian DIDI study. J Int AIDS Soc 2013;16:18591.

52. Koenig MA, Zablotska I, Lutalo T, et al. Coerced first intercourse and reproductive health among adolescent women in Rakai, Uganda. Int Fam Plan Perspect 2004;30:156-63.

53. Van der Straten A. Sexual coercion, physical violence and HIV infection among women in steady relationships in kigali. rwanda, 1998.

54. McCarraher D, Cuthbertson C, Kung'u D, et al. Sexual behavior, fertility desires and unmet need for family planning among home-based care clients and caregivers in Kenya. AIDS Care 2008;20:1057-65.

55. Craft SM, Delaney RO, Bautista DT, et al. Pregnancy decisions among women with HIV. AIDS Behav 2007;11:927-35.

56. Chander G, Lau B, Moore RD. Hazardous alcohol use: a risk factor for non-adherence and lack of suppression in HIV infection. $J$ Acquir Immune Defic Syndr 2006;43:411-7.
57. Cook RL, Sereika SM, Hunt SC, et al. Problem drinking and medication adherence among persons with HIV infection. J Gen Intern Med 2001;16:83-8.

58. Stein MD, Anderson B, Charuvastra A, et al. Alcohol use and sexual risk taking among hazardously drinking drug injectors who attend needle exchange. Alcohol Clin Exp Res 2001;25:1487-93.

59. Jaquet A, Wandeler G, Nouaman M, et al. Alcohol use, viral hepatitis and liver fibrosis among HIV-positive persons in West Africa: a crosssectional study. J Int AIDS Soc 2017;19:1-10.

60. Barve S, Kapoor R, Moghe A, et al. Focus on the liver: alcohol use, highly active antiretroviral therapy, and liver disease in HIV-infected patients. Alcohol Res Health 2010;33:229-37.

61. Santos GM, Emenyonu NI, Bajunirwe F, et al. Self-reported alcohol abstinence associated with ART initiation among HIV-infected persons in rural Uganda. Drug Alcohol Depend 2014:134:151-7.

62. Wandera B, Tumwesigye NM, Nankabirwa Jl, et al. Alcohol Consumption among HIV-Infected Persons in a Large Urban HIV Clinic in Kampala Uganda: A Constellation of Harmful Behaviors. PLoS One 2015;10:e0126236.

63. Benefo KD. Determinants of condom use in Zambia: a multilevel analysis. Stud Fam Plann 2010;41:19-30.

64. Volk JE, Koopman C. Factors associated with condom use in Kenya: a test of the health belief model. AIDS Educ Prev 2001;13:495-508.

65. Ukwuani FA, Tsui AO, Suchindran CM. Condom use for preventing HIV infection/AIDS in sub-Saharan Africa: a comparative multilevel analysis of Uganda and Tanzania. J Acquir Immune Defic Syndr 2003;34:203-13.

66. Serwadda D, Wawer MJ, Musgrave SD, et al. HIV risk factors in three geographic strata of rural Rakai District, Uganda. AIDS 1992;6:983-90.

67. Diabaté S, Alary M, Koffi CK. Short-term increase in unsafe sexual behaviour after initiation of HAART in Côte d'Ivoire. AIDS 2008;22:154-6. 